\title{
Summertime European heat and drought waves induced by wintertime Mediterranean rainfall deficit
}

\author{
R. Vautard, ${ }^{1,2}$ P. Yiou, ${ }^{1}$ F. D’Andrea ${ }^{2}$ N. de Noblet, ${ }^{1}$ N. Viovy, ${ }^{1}$ C. Cassou, ${ }^{3}$ J. Polcher, ${ }^{2}$ \\ P. Ciais, ${ }^{1}$ M. Kageyama, ${ }^{1}$ and Y. Fan ${ }^{4}$ \\ Received 25 August 2006; accepted 23 February 2007; published 13 April 2007.
}

[1] The risk of extreme heat waves in Europe like the unprecedented one of summer 2003 is likely to increase in the future, calling for increased understanding of these phenomena. From an analysis of meteorological records over 58 years, we show that hot summers are preceded by winter rainfall deficits over Southern Europe. Subsequent drought and heat spreads northward throughout Europe in early summer, due to atmospheric transport of anomalously warm and dry air from Southern Europe in southerly wind episodes. This is shown by the observations and supported by mesoscale meteorological sensitivity simulations for Summer 1994. Moreover previous winter and early spring rainfall frequency in the Mediterranean regions is correlated with summer temperature in central continental Europe. These results emphasize the critical role of the water reservoir in the soil of continental Mediterranean areas for the maintenance of European climate. Citation: Vautard, R., P. Yiou, F. D'Andrea, N. de Noblet, N. Viovy, C. Cassou, J. Polcher, P. Ciais, M. Kageyama, and Y. Fan (2007), Summertime European heat and drought waves induced by wintertime Mediterranean rainfall deficit, Geophys. Res. Lett., 34, L07711, doi:10.1029/2006GL028001.

\section{Introduction}

[2] Several models predict more frequent extreme weather events as human influence on climate increases [Easterling et al., 2000]. In Europe, the risk of extreme heatwaves like the one of Summer 2003 is likely to increase in the future [Beniston, 2004; Meehl and Tebaldi, 2004; Schär et al., 2004; Stott et al., 2004]. This episode demonstrated that heat waves in Europe have severe impacts on human health [World Health Organization, 2003], vegetation productivity [Ciais et al., 2005], and air quality [Vautard et al., 2005]. Yet, the underlying regional climate mechanisms through which these extremes develop and persist once established are not understood.

[3] In summer, when the large-scale westerly flow regime advecting rain over Europe weakens, the continental

\footnotetext{
${ }^{1}$ Laboratoire des Sciences du Climat et de l'Environnement, L'Institut Pierre-Simon Laplace, CEA, CNRS, UVSQ, Gif sur Yvette, France.

${ }^{2}$ Laboratoire de Météorologie Dynamique, Ecole Polytechnique, Palaiseau, France.

${ }^{3}$ Centre Européen de Recherche et de Formation Avancée en Calcul Scientifique, CNRS URA 1875, Toulouse, France.

${ }^{4}$ National Centers for Environmental Prediction, Camp Springs, Maryland, USA.

Copyright 2007 by the American Geophysical Union. 0094-8276/07/2006GL028001
}

weather is potentially influenced by parameters having a memory longer than a few days: sea-surface temperature and soil moisture. An anomalously warm tropical Atlantic ocean triggers an atmospheric stationary wavetrain propagating towards Europe [Ambrizzi et al., 1995] which favors the occurrence of anticyclonic weather regimes over the continent [Cassou et al., 2005]. Exposed to drier air, plants transpire more water, which empties the soil moisture reservoir. Dry soils then emit more sensible heat, inhibiting cloudiness and further increasing daytime temperature. In August 2003 a deficit of latent heat and an excess of sensible heat fluxes were found in European Centre for Medium Range Weather Forecasts analyses [Black et al., 2004]. As soil moisture availability also acts as a trigger of storm precipitation, particularly in drier areas of Europe [Schär et al., 1999], a dry soil inhibits convective cloud formation, increasing daytime shortwave radiation and further increasing evapotranspiration.

[4] Soil moisture varies slowly, on the time scale of weeks to months and thus carries a memory of the previous month's climate [Shukla and Mintz, 1982; Huang and van den Dool, 1992] until summertime. For instance heat waves in the Central U.S. plains are often preceded by a drought [Chang and Wallace, 1987]. In Europe, modeling studies also showed a high sensitivity of summer climate to soil moisture [Rowntree and Bolton, 1983], while neighboring sea-surface temperatures have a more limited influence on continental temperatures, as shown by sensitivity model experiments for Summer 2003 [Ferranti and Viterbo, 2006].

[5] However the link between summer heat in Europe and the regional structure of the preceding winter's climate has never been investigated from observations of temperature and rainfall. Using historical weather stations data from more than a hundred of sites in Europe [Klein Tank et al., 2002], we analyze the climate of the years with the ten hottest summers between 1948 and 2005, and propose a regional climate mechanism that links summer droughts and heat waves in central Europe to preceding winter's rainfall deficit in Mediterranean areas. This mechanism is tested with sensitivity simulations from the 5th generation Penn State mesoscale meteorological model MM5 [Dudhia, 1993]. In section 2 observational results are presented and model results are presented in section 3. A discussion follows in section 4 .

\section{Regional Climate of Hot Summer Years}

[6] The 10 hottest summers among the period 19482005 are selected according to their June-July-August (JJA) observed linearly detrended daily maximum temper- 


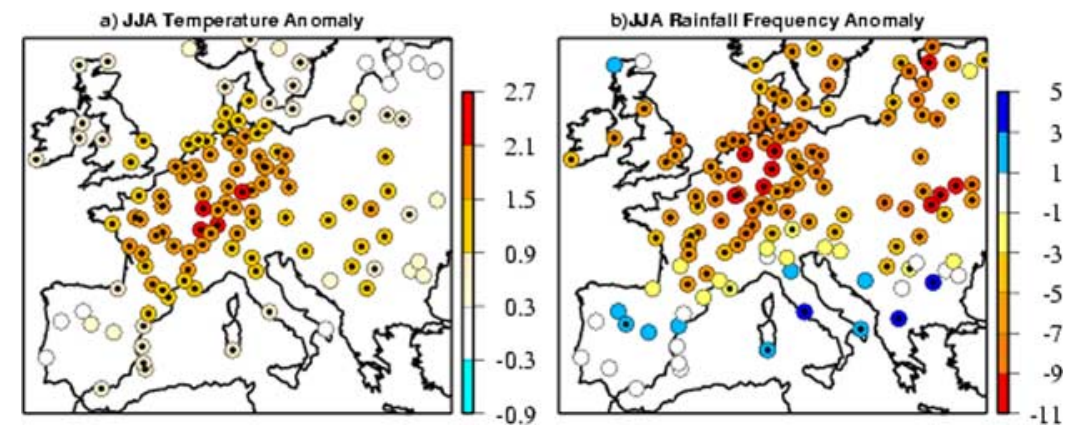

Figure 1. (a) Summertime (JJA) daily maximum temperature anomaly $\left({ }^{\circ} \mathrm{C}\right)$ averaged over the 10 hottest summers in the 1948-2004 period. (b) Same as for Figure 1a but for JJA anomaly of the frequency of rainy events (\% of days when cumulated precipitation exceeds $0.5 \mathrm{~mm}$ ). Stations where the anomaly is significant at the $90 \%$ level are marked by a black bullet.

ature $\left(\mathrm{T}_{\max }\right)$, (see the auxiliary material ${ }^{1}$ for selection of sites), taken from the European Climate Assessment blended observed data [Klein Tank et al., 2002], and averaged over a domain covering western Europe $\left(10^{\circ} \mathrm{W}\right.$ $\left.30^{\circ} \mathrm{E} ; 35^{\circ} \mathrm{N}-60^{\circ} \mathrm{N}\right)$. Years before 1948 are not considered because many observations are missing, thus altering the homogeneity of the set of observations. The number of selected summers (10) is arbitrary but our results are robust for numbers ranging from 5 to 20 .

[7] The selected years are 1950, 1952, 1959, 1964, 1976, 1983, 1992, 1994, 1995 and 2003 (see Table S1 of the auxiliary material for the climate characteristics of these years). All hot summers exhibit a simultaneous deficit both in cumulative precipitation and in rainfall frequency, in percent of days, showing that summer heat is always accompanied by a rainfall deficit. In this article, we prefer using rainfall frequency than cumulative rainfall because of its more homogeneous spatial distribution, due to the inherent small-scale variability of summertime rainfall amount.

[8] The amplitude of the average hot summer JJA T $\max$ anomalies exhibits largest values in central-eastern France, Switzerland and Germany (Figure 1a). The associated deficit in rainfall frequency is most pronounced in Northern temperate Europe (Figure 1b). The small rainfall increase in southern Europe is hardly significant due to the small variability of summer precipitation in Mediterranean areas, where often no rain at all is observed during the whole summer.

[9] We expect dry soils in spring over Europe to favor and maintain hot summers. However the analysis of both the rainfall frequency of the winter and spring preceding hot summers (Figures 2a, 2b, and 2c) exhibits a more subtle sequence. Interestingly there is no rainfall anomaly over Northern Europe in winter and early spring, but a significant rainfall deficit is found over Mediterranean areas (Figure 2a). Rainfall deficit then extends northward through central and northern Europe in May and June (Figures 2b and $2 \mathrm{c}$ ). This specific northward propagation sequence can be seen in most of the 10 selected years taken individually, although with significant variations from year to year. This

\footnotetext{
${ }^{1}$ Auxiliary material data set is available at $\mathrm{ftp} / / \mathrm{ftp}$.agu.org./apend/gl/ 2006gl028001. Other auxiliary material files are in the HTML.
}

sequence of anomalies is also found, with increased statistical significance but decreased amplitude, when averaging over more than 10 hot summers (typically 20), showing its robustness. Northward progression of drought is also found in the simulations of soil moisture and surface fluxes carried out with two different land-surface schemes [Fan and van den Dool, 2004; Verant et al., 2003; Krinner et al., 2005], as shown in Figure S1.

[10] One qualitative explanation for this drought propagation is as follows. Spring soil moisture deficit in Southern Europe inhibits local convective cloud formation and enhances local sensible heat fluxes (Figure S1). In early summer, during sequences of southerly wind regimes, the flow delivers drier, warmer and less cloudy air masses over central and Northern Europe. Cloudiness decline together with temperature increase over Northern Europe induce a stronger local evapotranspiration and more water is removed from the soil, as a positive feedback. As an additional feedback, drier air transported northward in or above the boundary layer leads to less convective air masses in Central Europe in southerly wind conditions, reinforcing the drought. This feedback is symmetrical to that found in the study of the wet summer of 1993 over the U. S. [Beljaars et al., 1996]. A net northward atmospheric transport of heat excess and moisture deficit could therefore link Mediterranean wintertime drought with Northern Europe summertime heat. A symmetrical mechanism starting from a soil drought in Northern Europe could also increase summer heat in the south but is less likely due to lower temperature and radiation, even after wintertime rainfall deficit. Therefore summer heat in Europe should be most sensitive to southern Europe wintertime rainfall deficit.

[11] This mechanism is tested by comparing maximal temperature and rainfall frequency hot-summer anomalies for southerly and northerly local surface wind conditions as taken from NCEP reanalyses [Kalnay et al., 1996]. In early hot summers southerly winds carry larger positive temperature and negative rainfall anomalies than northerly winds in most stations in continental Europe (Figures 2d and 2e). This is a clear indication of an early-summer net northward transport of heat excess and moisture deficit by the atmosphere, and consistently less rain in southerly wind conditions. The same differences computed from a partition between Easterly and Westerly winds do not yield statisti- 


\section{Rainfall Frequency anomaly}
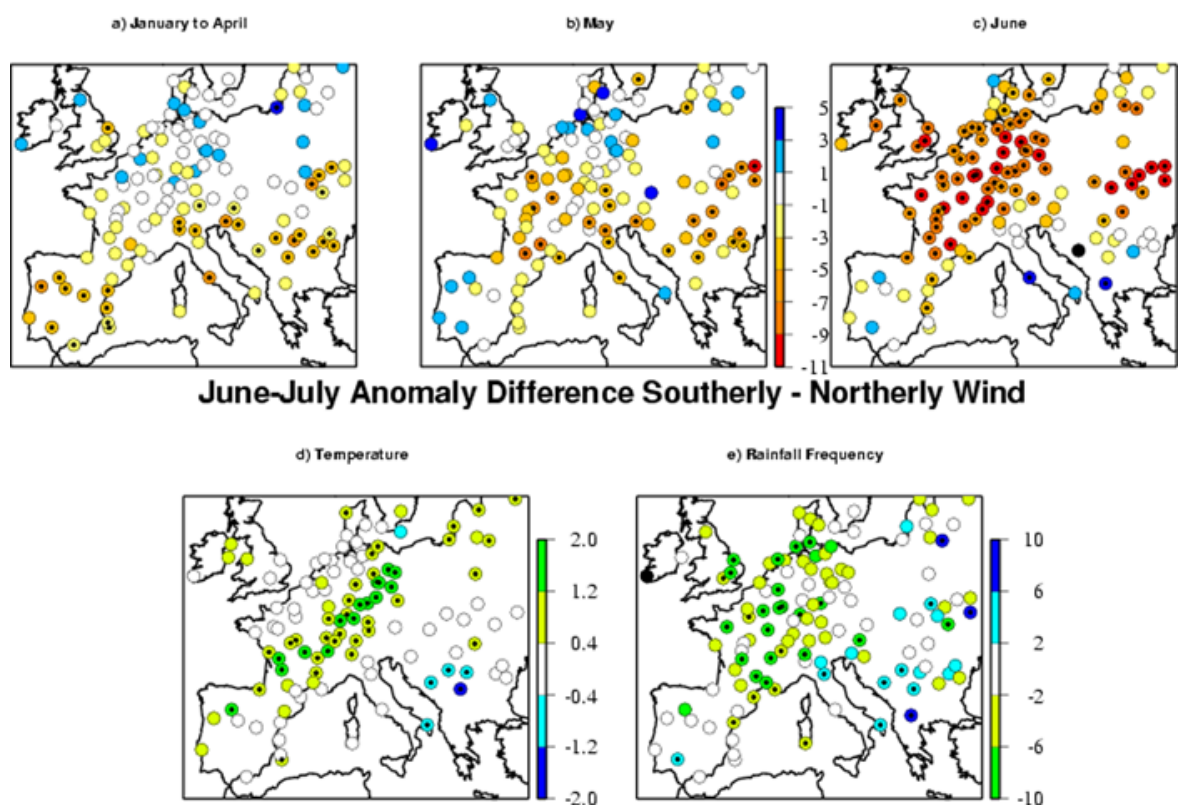

Figure 2. (a) Average rainfall frequency anomaly (\% of days) (January-April) for the 10 years containing the hottest summers listed in Table S1 of the auxiliary material. (b) Same as for Figure 2a but for averages of the month of May only. (c) Same as for Figure 2a but for June. (d) Difference in the early summer (June and July) maximal hot-summer temperature anomalies between when southerly and northerly wind occurs at the station. At each station, days are classified into 2 classes according to the sign of the mean daily surface meridional wind field. The 58 -year average maximal temperature is calculated and subtracted from the hot-summer average to obtain mean anomalies. The difference between "southerly" and "northerly" mean anomalies is shown in Figure 2d. Figure 2d shows that temperature anomalies, in the 10 hottest summers, are higher in southerly wind conditions than in northerly wind conditions. (e) Same as for Figure 2d but for rainfall frequency ( $\%$ of days). Stations where the differences are significant at the $90 \%$ level are marked with a black bullet.

cally significant results, showing, by contrast, the absence of net longitudinal transport of heat and moisture.

\section{Sensitivity Mesoscale Simulations}

[12] The northward propagation of Mediterranean droughts found in observational data is confirmed by regional model simulations over Europe. Using the mesoscale MM5 model [Dudhia, 1993], twin simulations have been carried out for the case of the typical hot summer of 1994. Both simulations start on 1 June 1994, and differ only by their initial soil moisture south of $46^{\circ} \mathrm{N}$ : In the "wet" simulation, an initial volumetric soil moisture content of $30 \%$ is assumed while in the "dry" simulation it is only $15 \%$. North of $46^{\circ} \mathrm{N}$ initial soil moisture content is taken from the ERA40 ECMWF reanalysis data for both simulations.

[13] Assuming dryer soils in spring has a large effect in increasing the afternoon temperatures during July (Figure 3a). Soil moisture deficits induce warmer conditions by up to $5-6^{\circ} \mathrm{C}$ over the initially drier region (latitude $<46^{\circ} \mathrm{N}$ ) and by up to $2^{\circ} \mathrm{C}$ in regions further to the north, over France, Switzerland and Southern Germany (Figure 3a). The northward progression of the heat anomaly formed over the dryer Mediterranean soils is illustrated in Figure 3b. A parallel progression in soil moisture is also simulated, as shown in Figure 3c. Over much of Northern Europe, the dry-wet surface sensible heat flux difference increases by $10-30 \mathrm{~W} / \mathrm{m}^{2}$ between June and July following the heat and drought propagation. All along the simulated period the dry-wet energy budget difference at 12 UT is driven by a general increase of shortwave radiation due to reduced cloudiness even over Northern Europe (not shown).

[14] A careful examination of the simulations indicates that the northward progression of dry-wet heat and drought results from an efficient northward transport during transient southerly episodes that transient northerlies fail to compensate. Also, in the dry simulation, the initial Mediterranean drought leads to slightly higher pressures over the whole continent in the mid troposphere, a feedback process that makes the low troposphere more stable and therefore less cloudy.

[15] These modeling results are likely to be conservative. First, the setting of fixed lateral boundary conditions combined with the relatively small size of the model domain could inhibit the full development of synoptic-scale anticyclonic circulations triggered by soil moisture. Our simulations therefore only address part of the soil-atmosphere feedback. Second the MM5 model simulations have a cold bias of up to a few degrees as compared to observations over some continental areas (not shown). Model daytime temperatures closer to reality would probably increase the drought build-up, reinforce the heat amplification and northward progression mechanism.

[16] Such a northward progression of heat, was also found in similar mesoscale simulations for other years, with lower amplitude than for Summer 1994. A complete dis- 


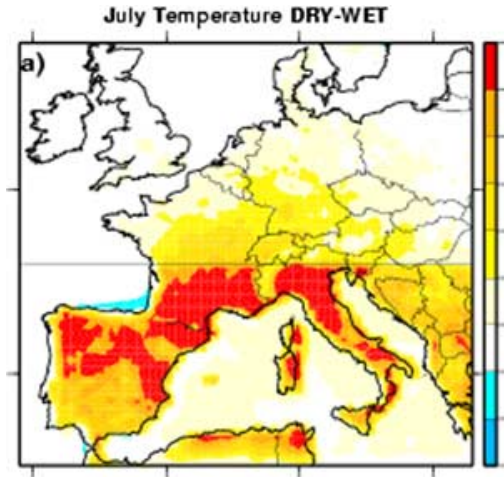

July-June Difference Soil Moisture DRY-WET

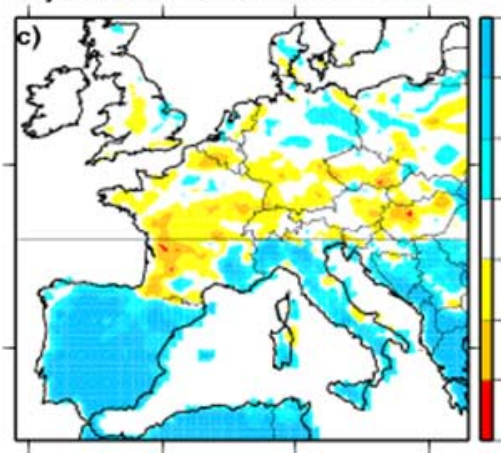

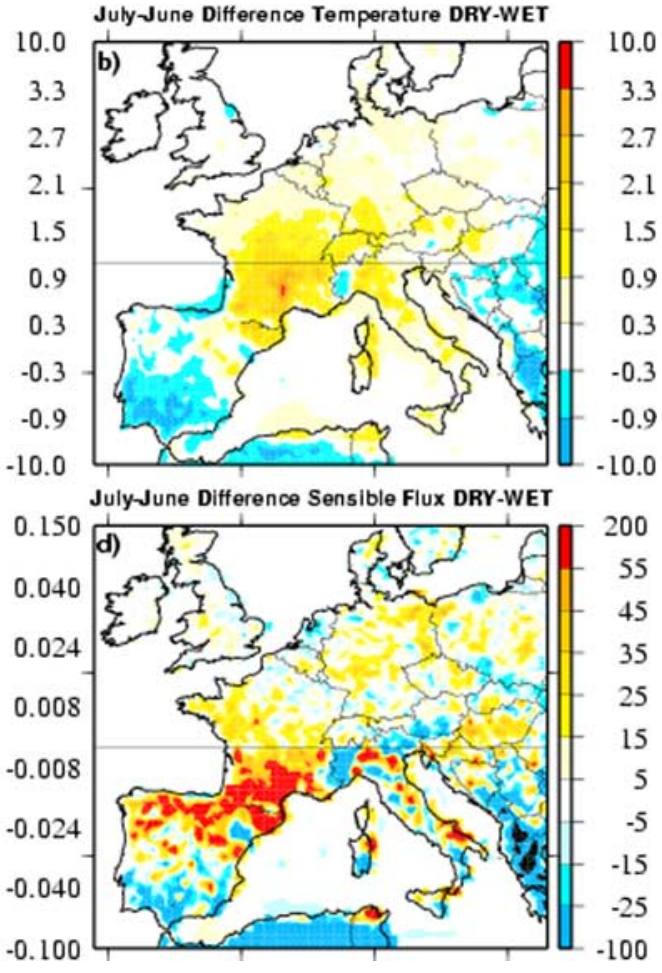

Figure 3. Results of the twin simulations ("dry" and "wet") of summer 1994 using the MM5 mesoscale model. The simulations were initialized on 1 June south of $46^{\circ} \mathrm{N}$ (indicated by line), "dry" using a volumetric soil moisture content (fraction of water in soil) of 0.15, and "wet" using 0.30. (a) Difference between "dry" and "wet" $15 \mathrm{~h}$ UT $2 \mathrm{~m}$ temperature averaged over the month of July 1994. (b) Difference between the July and June dry-wet differences in 15 h UT 2 m temperatures. (c) Same as for Figure 3b (June-July increment of the dry-wet differences), but for volumetric soil moisture content. (d) Same as for Figure 3b, but for the sensible heat flux, in $\mathrm{W} / \mathrm{m}^{2}$, at $12 \mathrm{~h} \mathrm{UT}$.

cussion of several years of simulations, together with a more quantitative analysis will be given in a future article.

\section{Discussion}

[17] A southern European winter drought is a necessary but not sufficient condition for the development of general summer heat and subsequent episodic heat waves. Hot summers are also associated with an increased frequency of anticyclonic weather regimes [Cassou et al., 2005]. In the course of the summer, the northward progression of the drought signal can be interrupted by adverse series of synoptic weather systems bringing rain and replenishing groundwater. Nevertheless, we found that winter-early spring rainfall deficit in southern Europe remains a good predictor of summer temperature. A significant high correlation, $(r=-0.55)$ is found between the time series of January to May average anomalies in the frequency of rainy events in Southern Europe (South of $46^{\circ} \mathrm{N}$ in the studied domain) and the detrended summer $\mathrm{T}_{\max }$ anomaly (Figure 4). All hot summers have a negative or vanishing anomaly of rainfall frequency over Southern Europe, except 1994, where wintertime precipitation deficit is shifted southward (see also Table S1). Mediterranean areas were also described to be the most sensitive to the precipitationsoil moisture feedback in a regional model [Schär et al., 1999]. Also, note that the regional mechanism described in this article is consistent with the predictability of European summer temperatures from wintertime North-Atlantic sea

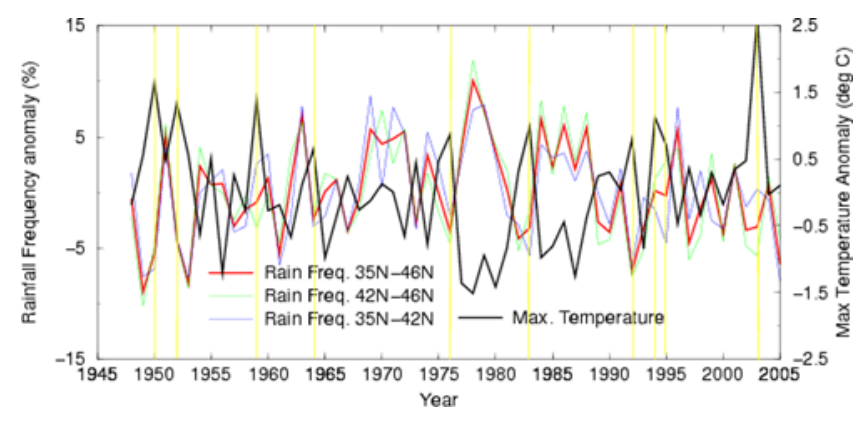

Figure 4. Detrended summertime (JJA) daily maximum temperature anomalies, averaged over European stations, as a function of year (black), together with the detrended anomaly of rainfall frequency averaged in the $35^{\circ} \mathrm{N}-46^{\circ} \mathrm{N}$ latitude band during preceding winter and early spring (January to May) (red). Temperature anomalies are in ${ }^{\circ} \mathrm{C}$ while precipitation frequencies anomalies are in \% of days. The correlation between the two sets of values is -0.55 . In order to assess the sensitivity of this latitude band for precipitation frequency, it is split into 2 latitude bands for which the time series are also calculated: $42^{\circ} \mathrm{N}-46^{\circ} \mathrm{N}$ (green) and $35^{\circ} \mathrm{N}-42^{\circ} \mathrm{N}$ (blue). Yellow bars indicate the selected 10 hottest summers. 
surface temperatures [Colman and Davey, 1999], these latter being sensitive, like Mediterranean soil moisture, to mean wintertime North-Atlantic atmospheric circulation.

[18] We have shown that hot summers in Europe are preceded by drought initiated in winter by a precipitation deficit over Mediterranean areas. Observations and model simulations indicate that the two phenomena are linked. The persistence of a drier weather over Southern Europe, as witnessed during the last decade, may therefore be one more reason to fear an increase in the frequency of summer heat waves throughout Europe in the future. Our results put a strong constraint on the ability of climate models to represent adequately the interactions between soil, vegetation, fluxes and transport at small scale in order to predict summer climate variability and trend over the European continent.

[19] Acknowledgments. We are thankful to Peter Rayner (LSCE) for his careful reading, scientific comments and numerous corrections brought to the manuscript. ECA data were downloaded from the web site http:// eca.knmi.nl and NCEP data from the ftp site ftp.cdc.noaa.gov. Map figures were constructed with the GMT free software, and other figures with the XMGR software.

\section{References}

Ambrizzi, T., B. J. Hoskins, and H. Hsu (1995), Rossby wave propagation and teleconnection patterns in austral winter, J. Atmos. Sci, 52, 36613672 .

Beljaars, A. C. M., P. Viterbo, M. J. Miller, and A. K. Betts (1996), The anomalous rainfall over the United States during July 1993: Sensitivity to land surface parameterization and soil moisture anomalies, Mon. Weather Rev., 124, 362-383.

Beniston, M. (2004), The 2003 heat wave in Europe: A shape of things to come? An analysis based on Swiss climatological data and model simulations, Geophys. Res. Lett., 31, L02202, doi:10.1029/2003GL018857.

Black, E., M. Blackburn, G. Harrison, B. Hoskins, and J. Methven (2004), Factors contributing to the summer 2003 European heatwave, Weather, 59, 217-221.

Cassou, C., L. Terray, and A. S. Phillips (2005), Tropical Atlantic influence on European heat waves, J. Clim., 18, 2805-2811.

Chang, F.-C., and J. M. Wallace (1987), Meteorological conditions during heat waves and droughts in the United States Great Plains, Mon. Weather Rev., $115,1253-1269$.

Ciais, P., et al. (2005), An unprecedented reduction in the primary productivity of Europe during 2003 caused by heat and drought, Nature, 437, 529-533.

Colman, A., and M. Davey (1999), Prediction of summer temperature, rainfall and pressure in Europe from preceding winter North Atlantic Ocean temperature, Int. J. Climatol., 19, 513-536.

Dudhia, J. A. (1993), Nonhydrostatic version of the Penn State-NCAR Mesoscale Model: Validation tests and simulation of an Atlantic cyclone and cold front, Mon. Weather Rev., 121, 1493-1513.
Easterling, D. R., G. A. Meehl, C. Parmesan, S. A. Changnon, T. R. Karl, and L. O. Mearns (2000), Climate extremes: Observations, modeling and impacts, Science, 289, 2068-2074.

Fan, Y., and H. M. van den Dool (2004), Climate Prediction Center global monthly soil moisture data set at $0.5^{\circ}$ resolution for 1948 to present, J. Geophys. Res., 109, D10102, doi:10.1029/2003JD004345.

Ferranti, L., and P. Viterbo (2006), The European summer of 2003: Sensitivity to soil water initial conditions, J. Clim., 19, 3659-3680.

Huang, J., and H. M. van den Dool (1992), Monthly precipitation-temperature prediction over the United States, J. Clim., 13, 1111-1132.

Kalnay, E., et al. (1996), The NMC/NCAR 40-year reanalysis project, Bull. Am. Meteorol. Soc., 77, 437-471.

Klein Tank, A. M., et al. (2002), Daily dataset of 20th-century surface air temperature and precipitation series for the European Climate Assessment, Int. J. Climatol., 22, 1441-1453.

Krinner, G., N. Viovy, N. de Noblet-Ducoudré, J. Ogée, J. Polcher, P. Friedlingstein, P. Ciais, S. Sitch, and I. C. Prentice (2005), A dynamic global vegetation model for studies of the coupled atmosphere-biosphere system, Global Biogeochem. Cycles, 19, GB1015, doi:10.1029/ 2003 GB002199.

Meehl, G. A., and C. Tebaldi (2004), More intense, more frequent and longer lasting heat waves in the 21st century, Science, 305, 994-997.

Rowntree, P. R., and J. A. Bolton (1983), Simulation of the atmospheric response to soil-moisture anomalies over Europe, Q. J. R. Meteorol. Soc., 109, $501-526$.

Schär, C., D. Lüthi, and U. Beyerle (1999), The soil-precipitation feedback: A process study with a regional climate model, J. Clim., 12, 722-741.

Schär, C., P. L. Vidal, D. Lüthi, C. Frei, C. Häberli, M. A. Liniger, and C. Appenzeller (2004), The role of increasing temperature variability in European summer heatwaves, Nature, 427, 332-336.

Shukla, J., and Y. Mintz (1982), Influence of land-surface evapotranspiration on the Earth's climate, Science, 215, 1498-1501.

Stott, P., D. A. Stone, and M. Allen (2004), Human contribution to the European heatwave of 200,3, Nature, 432, 610-614.

Vautard, R., C. Honoré, M. Beekmann, and L. Rouil (2005), Simulation of ozone during the August 2003 heat wave and emission control scenarios, Atmos. Environ., 39, 2957-2967.

Verant, S., K. Laval, J. Polcher, and M. Castro (2003), Sensitivity of the continental hydrological cycle to the spatial resolution over the Iberian peninsula, J. Hydrometeorol., 5, 267-285.

World Health Organization (2003). The health impacts of 2003 summer heat-waves, briefing notes for the delegations of the fifty-third session of the WHO (World Health Organization) regional committee for Europe, 12 pp., Geneva, Switzerland.

C. Cassou, Centre Européen de Recherche et de Formation Avancée en Calcul Scientifique, CNRS URA 1875, 42 Avenue G. Coriolis, 31057 Toulouse Cedex 01, France.

P. Ciais, N. de Noblet, M. Kageyama, R. Vautard, N. Viovy, and P. Yiou, Laboratoire des Sciences du Climat et de l'Environnement, L'Institut PierreSimon Laplace, CEA, CNRS, UVSQ, F-91191 Gif sur Yvette, France. (robert.vautard@cea.fr)

F. D'Andrea and J. Polcher, Laboratoire de Météorologie Dynamique, Ecole Polytechnique, F-91128 Palaiseau Cedex, France.

Y. Fan, National Centers for Environmental Prediction, 5200 Auth Road, Camp Springs, MD 20746, USA. 